ACCEPTED MANUSCRIPT

\title{
Multichannel ZnO Nanowire Field Effect Transistors by Lift-off Process
}

To cite this article before publication: Martin Ebert et al 2018 Nanotechnology in press https://doi.org/10.1088/1361-6528/aad4c5

\section{Manuscript version: Accepted Manuscript}

Accepted Manuscript is "the version of the article accepted for publication including all changes made as a result of the peer review process, and which may also include the addition to the article by IOP Publishing of a header, an article ID, a cover sheet and/or an 'Accepted Manuscript' watermark, but excluding any other editing, typesetting or other changes made by IOP Publishing and/or its licensors"

This Accepted Manuscript is @ 2018 IOP Publishing Ltd.

During the embargo period (the 12 month period from the publication of the Version of Record of this article), the Accepted Manuscript is fully protected by copyright and cannot be reused or reposted elsewhere.

As the Version of Record of this article is going to be / has been published on a subscription basis, this Accepted Manuscript is available for reuse under a CC BY-NC-ND 3.0 licence after the 12 month embargo period.

After the embargo period, everyone is permitted to use copy and redistribute this article for non-commercial purposes only, provided that they adhere to all the terms of the licence https://creativecommons.org/licences/by-nc-nd/3.0

Although reasonable endeavours have been taken to obtain all necessary permissions from third parties to include their copyrighted content within this article, their full citation and copyright line may not be present in this Accepted Manuscript version. Before using any content from this article, please refer to the Version of Record on IOPscience once published for full citation and copyright details, as permissions will likely be required. All third party content is fully copyright protected, unless specifically stated otherwise in the figure caption in the Version of Record.

View the article online for updates and enhancements. 


\title{
Multichannel ZnO Nanowire Field Effect Transistors by Lift-off Process
}

\author{
M. Ebert ${ }^{a}$, N.A.B. Ghazali ${ }^{a}$, K.S. Kiang ${ }^{a}$, I. Zeimpekis ${ }^{a}$, B. \\ Maerz $^{b}$, M. R. R. de Planque ${ }^{a}$, H. M. H. Chong ${ }^{a}$ \\ ${ }^{a}$ School of Electronics and Computer Science, Faculty of Physical Sciences and \\ Engineering, University of Southampton, SO17 1BJ, UK \\ ${ }^{b}$ Department of Materials, Loughborough University, LE11 3TU, UK \\ E-mail: M.Ebert@soton.ac.uk
}

July 2018

\begin{abstract}
.
This paper describes a new low cost top-down fabrication process, which makes it possible to define nanowire field effect transistor (NWFET) arrays with different numbers of nanowires simultaneously and/systematically compare their electrical performance. The main feature of this process is a developed bilayer photoresist pattern with a retrograde profile, which enables the modification of the nanowire in width, length, height and the number of transistor channels. The approach is compatible with low cost manufacture without electron beam lithography and benefits from process temperatures below $190^{\circ} \mathrm{C}$. Process reliability has been investigated by SEM, TEM and AFM. Electrical measurements demonstrate enhancement mode transistors, which show a scalable correlation between the number of nanowires and the electrical characteristics. Devices with 100 nanowires exhibit the best performance with a high field effect mobility of $11.0 \mathrm{~cm}^{2} / \mathrm{Vs}$, on/off current ratio of $3.97 \times 10^{7}$ and subthreshold swing of $0.66 \mathrm{~V} /$ dec.
\end{abstract}

Keywords: zinc oxide ( $\mathrm{ZnO})$, field effect transistor (FET), nanowire, top-down fabrication

\section{Introduction}

One-dimensional (1D) nanostructures such as nanowires, nanotubes, nanorods and nanoribbons have been investigated in numerous studies because of their exceptional electrical and optical properties [1]. Nanowire field effect transistors (FET) are of interest for sensor applications [2], [3], including the detection and quantification of biomolecules such as enzymes or DNA [4, [5], 6]. Compared to silicon, ZnO exhibits a wide direct band gap $\left(E_{g}=3.37 \mathrm{eV} @ 300 \mathrm{~K}\right)$, which allows a high sensitivity [7], 8].

ZnO NWFETs have been fabricated with either bottom-up or top-down techniques

[9]. Typical bottom-up approaches involve nanowire synthesis by chemical vapour 
deposition (CVD) or a hydrothermal process, both of which result in high quality nanowires in terms of monocrystallinity, homogeneous morphology and a high aspect ratio, although the nanowire width and length can vary [10], [11]. However, bottom-up fabricated nanowires are difficult to be deposited at well defined positions on device substrates, which reduces the NWFET yield after subsequent top-down process steps that define other elements such as the source and drain electrodes at predetermined positions [12], [13], [14]. Recent investigations on bottom up technqiues show very controllable defenition of the nanowires to the substrate, but are also very cost intensive due to the use of electron beam lithography [15], [16]. To avoid this complex hybrid of bottom-up and top-down fabrication, other groups have explored an exclusively top-down strategy. Hereby, the main idea of the nanowire generation involves the spacer technique, where deposition and etching processes are used to create a nonreversible template [17]. This strategy exploits the lithography-determined position of the spacer, and therefore the nanowire location, on the device substrate. Moreover, the NWFET channel length, width and thickness can be varied to meet a range of performance specifications [18]. Recent studies on this fabrication approach have shown good transistor performance and also demonstrated biosensor functionality [19], [20]. Further improvement on the NWFET characteristics has been achieved by reducing the nanowire surface roughness, which is known to have a significant effect on the electrical properties of nanowires [21], [22]. However, the previously developed spacer technique has several disadvantages. The fabrication process is based on a non-reversible template and is not suitable for low temperature processes and hence precludes the use of polymer substrates. Furthermore, the nanowires are formed by anisotropic dry etching where ions and radicals from the plasma source are/implanted into the nanowires and change their top surface chemistry and hence their electrical properties [23]. Another problematic issue is non-uniformity of the back gate layer, associated with a poor control of the transistor channel [19]. Finally, although the spacer technique in principle enables a range of nanowire lengths and nanowire array sizes to be realized simultaneously on the same substrate, this has to date not been demonstrated.

In the present study, a new spacer-based fabrication approach was developed and scaling of the nanowire dimension and array size was demonstrated, enabling an analysis of the electrical characteristics of the various NWFET configurations. This process benefits from low temperatures, below $190{ }^{\circ} \mathrm{C}$. Two process steps, thermal oxidation and inductively coupled plasma etching, were eliminated. To reduce the impact of implanted ions into the $\mathrm{ZnO}$ crystal lattice during the anisotropic etch step, a removable bilayer photoresist pattern was developed to protect the $\mathrm{ZnO}$ from ion bombardment. Two different photoresist layers were patterned, coated with $\mathrm{ZnO}$ by plasma enhanced atomic layer deposition (PEALD) and etched. This lithography technology is well known for metal lift-off as it exhibits excellent undercut profiles [24], [25]. In this investigation two different photoresist layers are patterned and coated with $\mathrm{ZnO}$ by plasma enhanced atomic layer deposition (PEALD) and etched. Here we show that it can also improve control over the charge carrier concentration in the nanowire channel. 
Furthermore, the presented fabrication process can be adapted to allow the nanowire to be formed on a planar back gate dielectric thin film, which enables an improved back gate control. ZnO NWFET arrays are used in biosensing applications, but their scaling properties for different nanowire numbers have not been investigated [26], [27. Therefore, the ZnO NWFETs were manufactured as arrays with different numbers of nanowires (2 to 100) and with different channel lengths $(5 \mu \mathrm{m}$ to $45 \mu \mathrm{m})$. The structural and morphological properties of the final device were examined with Sscanning electron microscopy (SEM), transmission electron microscopy (TEM) and atomic force microscopy (AFM). All NWFETs arrays were electrically characterized, demonstrating excellent field effect transistor behavior. $I_{D} / V_{G S}$ measurements were performed to extract the transconductance, field effect mobility, threshold voltage and subthreshold slope. As a prototype device, the nanowires were fabricated on a silicon wafer, but due to the low temperatures the process is transferrable to low-cost silicate or polymer substrates.

\section{Experiment}

The developed process enables the fabrication of NWFETs at process temperatures below $190{ }^{\circ} \mathrm{C}$. Thermally oxidized silicon wafers with á silicon dioxide thickness of $100 \mathrm{~nm}$ were used as substrate material. The template for creating the nanowire was a two-layer photo resist pattern of lift-off resist (LOR3A, Microchem Corp.) and diluted negative resist (AZ2070 1:1.33 AZ EBR Solvent, Microchemicals GmbH). LOR3A consists of polymethylglutarimide (PMGI), which is not sensitive to UV exposure. This bottom layer acts as a sacrificial thin film, exhibiting excellent adhesion and high temperature stability. It is compatible with $\mathrm{g}_{-}, \mathrm{h}$-, i-line photo resists and can be developed with standard TMAH containing developers [28]. AZ2070 was chosen as it provides a very high stability against thermal softening. Due to the small feature target dimensions, a diluted version of the resist was used to achieve a film thickness of $400 \mathrm{~nm}$.

First, the LOR3A was spun at $5000 \mathrm{rpm}$ to a $178 \mathrm{~nm}$ thin film and baked 10 minutes on a hotplate at $190^{\circ} \mathrm{C}$ to increase the structural stability. The thickness of the LOR3A defines the gap height, where the nanowire is formed. For a $30 \mathrm{~nm}$ thick nanowire the gap needs to be at least $100 \mathrm{~nm}$ high to ensure an unobstructed deposition of the ZnO. To obtain $100 \mathrm{~mm}$, the LOR3A film was thinned in a $30 \mathrm{~s}$ developer bath containing 2.38 $\%$ TMAH. After rinsing and drying, diluted AZ2070 was spun at $5000 \mathrm{rpm}$ on top of the LOR3A layer (figure1a)), then baked at $90{ }^{\circ} \mathrm{C}$ for $30 \mathrm{~s}$, exposed to UV $\left(40 \mathrm{~mJ} / \mathrm{cm}^{2}\right)$ and post-baked at $115{ }^{\circ} \mathrm{C}$ for $1 \mathrm{~min}$.

The resist development was carried out in two steps. First the wafer was developed for 1 minute in diluted AZ 726 MIF (Merck Performance Materials GmbH) until all unexposed resist was completely removed (figure 1b)). To achieve a gap at the bottom resist layer it was necessary to harden the top layer to reduce its dissolution rate against TMAH. To this end, a flood exposure at $1 \mathrm{~J} / \mathrm{cm}^{2}$ and a $150{ }^{\circ} \mathrm{C}$ bake for 1 minute were carried out. The second development step etches the LOR3A to the desired gap width 


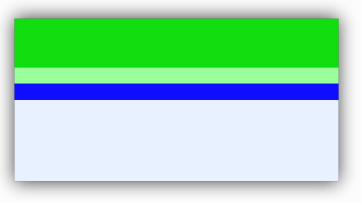

(a)

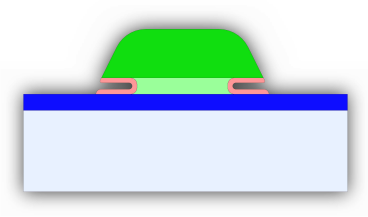

(e)

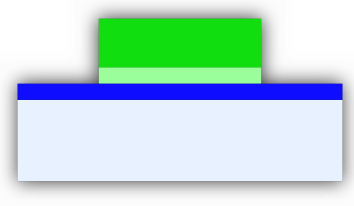

(b)

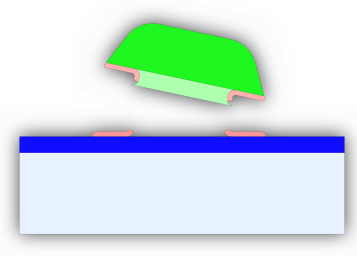

(f)

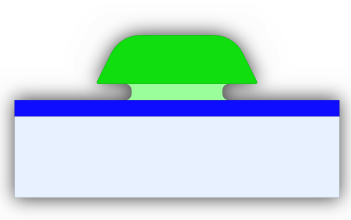

(c)

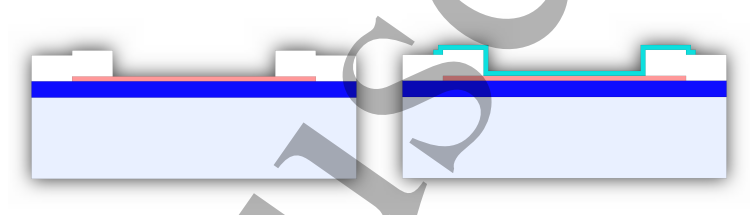

(g)

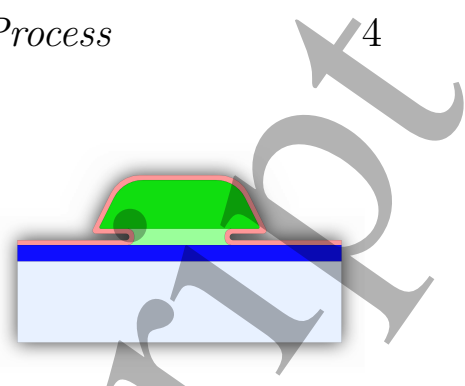

(d)

(h)

Si $\mathrm{SiO}_{2} \square$ LOR3A $\square$ AZ2070 verd. 1:1.33

$\mathrm{ZnO} \square \mathrm{Ti} / \mathrm{Au} \quad \square \mathrm{Al}_{2} \mathrm{O}_{3}$

Figure 1. Schematic process flow cross section of (a) spun LOR3A and diluted AZ2070 on oxidised silicon wafer, (b) resist pattern after first development, (c) resist pattern after hardbake and second development, (d) ZnO coated resist pattern by PEALD, (e) anisotropic dry etched pattern, (f) resist lift-off process, (g) metal pad formation along the nanowire, $(\mathrm{h})$ deposited and structured $\mathrm{Al}_{2} \mathrm{O}_{3}$ layer along the nanowire

of $250 \mathrm{~nm}$ (figure 1 $\mathrm{c}$ )). With this step it is possible to adjust the resulting nanowire width. Figure 2 a) shows a SEM cross section of the patterned resist. The pitch between each pattern is $5 \mu \mathrm{m}$ long.

Next, ZnO was deposited by PEALD (figure 1d)). PEALD has been used in spacerdefined double patterning and enabled low temperature deposition on photo resists [29]. Compared to thermal ALD processes PEALD uses an inductively coupled plasma (ICP) source to ionize $\mathrm{O}_{2}$ instead of a water tank for the oxygen supply of the $\mathrm{ZnO}$. This technique improves the range of the ALD process window and enables coating of the thin film at $150{ }^{\circ} \mathrm{C}$ without compromising the conformality of the layer. A ZnO thickness of $30.92 \mathrm{~nm}$ was achieved using 218 ALD cycles with $100 \mathrm{~ms}$ diethylzinc (DEZ, $\left.\mathrm{Zn}\left(\mathrm{C}_{2} \mathrm{H}_{5}\right)_{2}\right)$ pulse, $4 \mathrm{~s}$ DEZ purge, $2.65 \mathrm{~s} \mathrm{O}_{2}$ plasma step with $100 \mathrm{~W}$ RF power and $4 \mathrm{~s} \mathrm{O}_{2}$ purge. A very conformal $\mathrm{ZnO}$ deposition was observed using scanning electron microscopy, where ZnO fills the patterned gap of the bilayer photo resist (figure 2 b)).

Subsequently the sample was etched anisotropically in an Argon ion beam etcher (IBE) (figure 19)). IBE has been used due to several benefits. Compared to plasma etching techniques, where the sample is placed within the plasma, IBE decouples the wafer from the plasma source and prevents unwanted uncontrollable side effects such as charging. Gas chemistries with $\mathrm{CHF}_{3}$ and $\mathrm{Cl}_{2}$ promote reactions of the $\mathrm{ZnO}$ and the photo resist and leave residues, for example $\mathrm{ZnF}_{2}$ and $\mathrm{ZnCl}_{2}$, which are hard to dissolve [30]. The etching process is better controlled due to the use of inert Argon gas. With a beam current of $300 \mathrm{~mA}$ and beam voltage of $500 \mathrm{~V}$, an etch rate of $17 \mathrm{~nm} / \mathrm{min}$ was achieved. Figure 2 c) shows the SEM cross section of the etched area, where the $\mathrm{ZnO}$ 


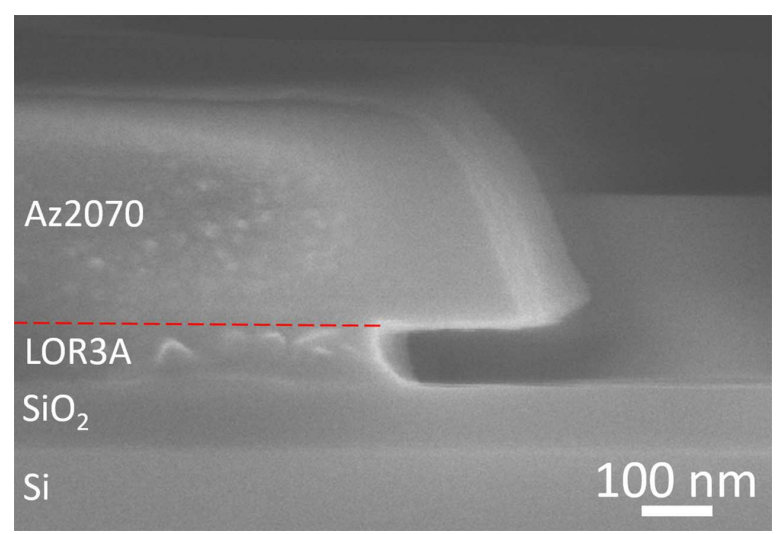

(a)

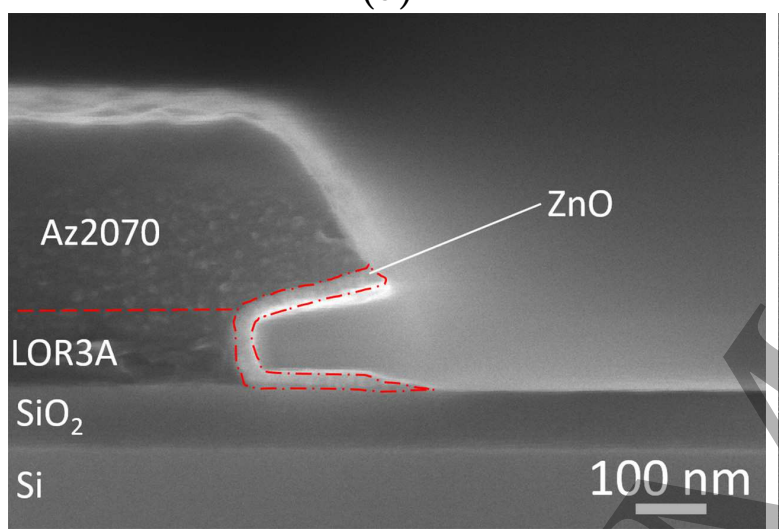

(c)

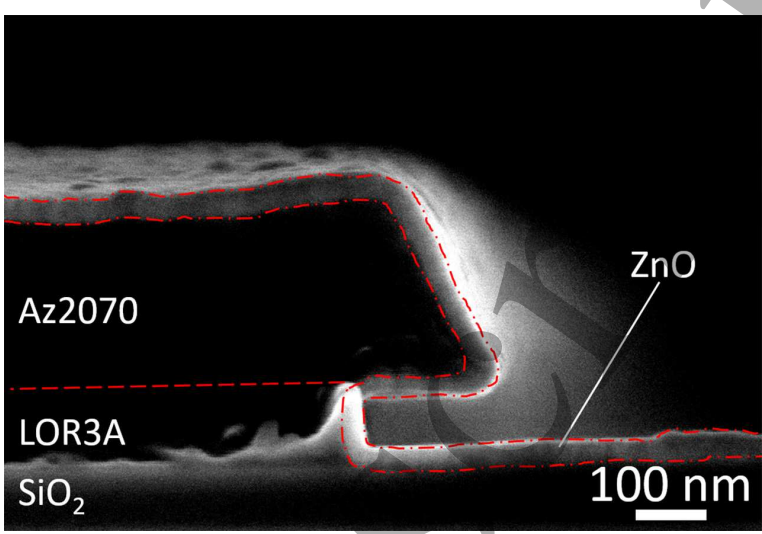

(b)

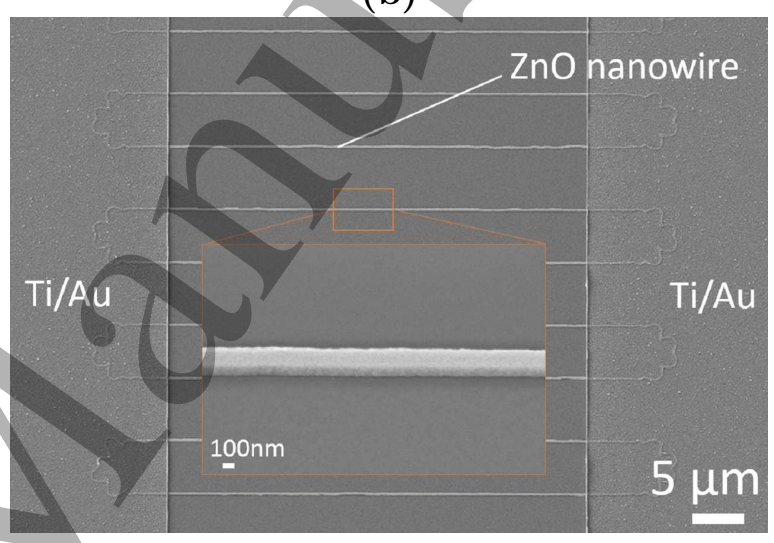

(d)

Figure 2. Scanning electron micrograph of (a) a cross section of the developed bilayer photo resist pattern, (b) a cross section of the $\mathrm{ZnO}$ coated photo resist pattern using PEALD, (c) a cross section of the $\mathrm{ZnO}$ coated resist pattern after IBE dry etch, (d) a top view of nanowire array with patterned $\mathrm{Ti} / \mathrm{Au}$ metal pads

remains at the gap area in the sidewall of the photo resist pattern.

The resist was then stripped by placing the sample into a N-methyl-2-pyrrolidone (NMP) ultrasonic bath at $80^{\circ} \mathrm{C}$. During the strip, the bilayer resist including the $\mathrm{ZnO}$ thin film on it's sidewall was lifted off and only a $\mathrm{ZnO}$ nanowire, which adheres on the substrate was left (figure 1f ) ) Ti/Au (10 nm / $150 \mathrm{~nm}$ ) was evaporated over a patterned AZ2070 negative resist and the lift-off technique was employed to form metal contacts at the source and drain region of the NWFET (figure 1 $\mathrm{g}$ )). The top view scanning electron micrograph from figure 2 d) shows a NWFET array with straight and regularly positioned nanowires. For depositing a $30 \mathrm{~nm} \mathrm{Al} \mathrm{O}_{3}$ passivation layer over the sample, a 300 cycles long PEALD process was used with $20 \mathrm{~ms}$ TMA pulse, $3 \mathrm{~s}$ TMA purge, $3 \mathrm{~s}$ $\mathrm{O}_{2}$ plasma step with $300 \mathrm{~W}$ RF power, $1 \mathrm{~s} \mathrm{O}_{2}$ purge. Metal contact areas were opened by another pattern and IBE etch of the $\mathrm{Al}_{2} \mathrm{O}_{3}$ with $300 \mathrm{~mA}$ beam current, $500 \mathrm{~V}$ beam voltage with an etchrate of $4 \mathrm{~nm} / \mathrm{min}$ (figure 1 $\mathrm{h}$ )).

For comparing the influences of different gate dielectric layers to the electrical performance of the NWFET another wafer was fabricated using an $\mathrm{Al}_{2} \mathrm{O}_{3}$ gate dielectric. 
The fabrication follows the same process like the other samples described above exempt the step of growing a thermal dry oxide. Here the sample was coated with a $30 \mathrm{~nm}$ thick $\mathrm{Al}_{2} \mathrm{O}_{3}$ thin film using PEALD with 300 cycles including a $20 \mathrm{~ms}$ TMA pulse, $3 \mathrm{~s}$ TMA purge, $3 \mathrm{~s} \mathrm{O}_{2}$ plasma step with $300 \mathrm{~W} \mathrm{RF}$ power and $1 \mathrm{~s} \mathrm{O}_{2}$ purge.

\section{Results}

\subsection{Characterisation of $\mathrm{ZnO}$ nanowire morphology}

Focused ion beam (FIB) was used for transmission electron microscopy lamella crosssection preparation of a nanowire. TEM was carried out at $200 \mathrm{kV}$ acceleration voltage using a FEI Tecnai F20 with a Gatan Multiscan CCD Camera. Nanowire cross section dimension exhibits $30.9 \mathrm{~nm}$ height and $257.4 \mathrm{~nm}$ width (figure 3a)). It can be seen that the nanowire consists of a polycrystalline structure with grain sizes up to $9.8 \mathrm{~nm} \mathrm{x}$ $28.3 \mathrm{~nm}$ (figure $3 \mathrm{~b}$ )), which accommodate with the publications of ZnO ALD processes [31], [32].
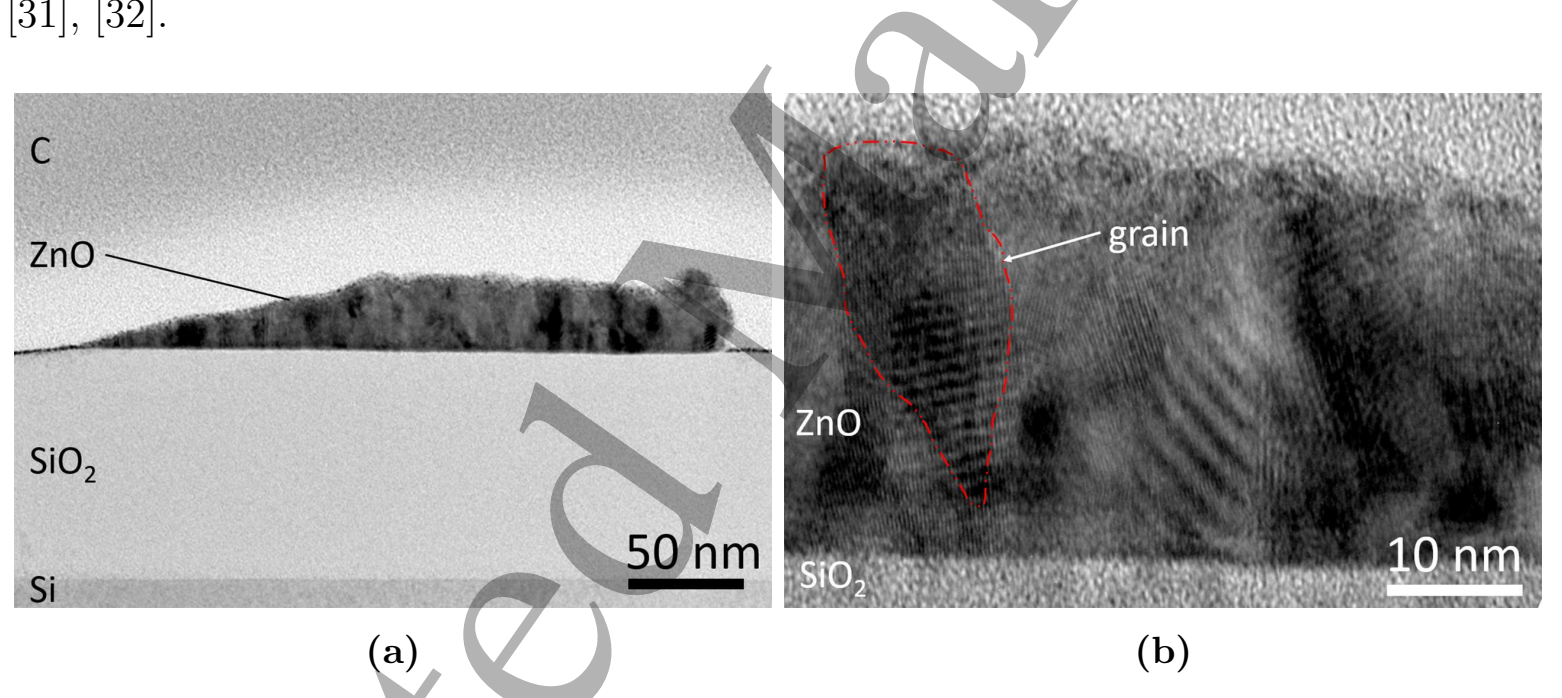

Figure 3. Bright field TEM cross section of a single nanowire; (a) overview, (b) detail

X-ray diffraction $2 \theta-\theta$ scans on a Rigaku Smartlab have been carried out to investigate the $\mathrm{ZnO}$ thin film crystal orientation. The grazing incidence $2 \theta$ scan, with 0.5 degree, in figure 4 a) shows peak position, which were identified as hexagonal structure $\mathrm{ZnO}$ [31]. The 002 diffraction peak is much stronger than theoretically expected, indicating that the $\mathrm{ZnO}$ thin film exhibits a strong c-axis orientation. However, as this scan is a grazing incidence $2 \theta$ scan, the scattering vector is inclined about $34 / 2$ $0.5=16.5$ degree from surface normal at 0002 diffraction condition. Therefore, the exact preferred orientation from this scan method can not be determined. Another in-plane diffraction scan with an incident angle of 0.2 degree has been carried out (figure 4 b)). The observed peak positions were identified as hexagonal structure ZnO. The 100 and 110 diffractions were stronger than theoretically expected, supporting the c-axis preferred orientation of the film. 


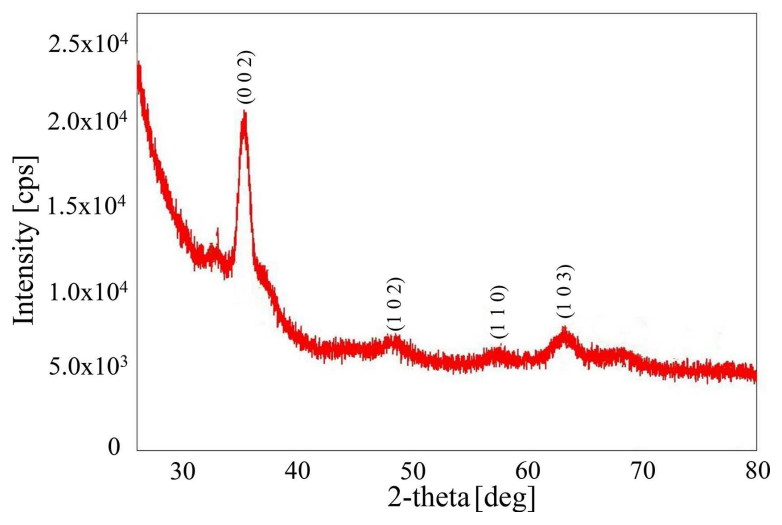

(a)

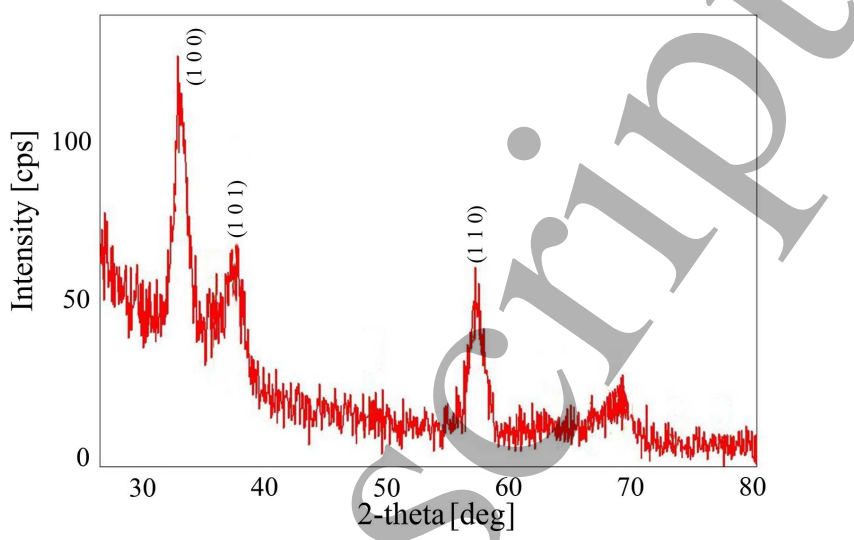

(b)

Figure 4. X-Ray diffraction spectra of deposited $\mathrm{ZnO}$ thin film: a) Grazing incidence $2 \theta$ scan; b) in-plane diffraction scan

\subsection{Surface roughness of the $\mathrm{ZnO}$ nanowire}

To investigate the $\mathrm{ZnO}$ surface morphology and roughness atomic force microscopy (AFM) was performed under ambient condition in intermittent non-contact mode with a PPP-NCHR probe from Nanosensors ${ }^{\mathrm{TM}}$. The tip is pyramid shaped and provides a $<10 \mathrm{~nm}$ tip radius of curvature and a height of $10 \mu \mathrm{m}$ to $15 \mu \mathrm{m}$. Image processing and analyses are performed using Gwydion software. The observed nanowire dimensions correspond to the TEM measurements. Figure 5 a) shows the AFM scan over the nanowire surface area with a length of $500 \mathrm{~nm}$. A surface roughness rms of $1.2 \mathrm{~nm}$ was extracted from figure $5 \mathrm{~b}$ ).

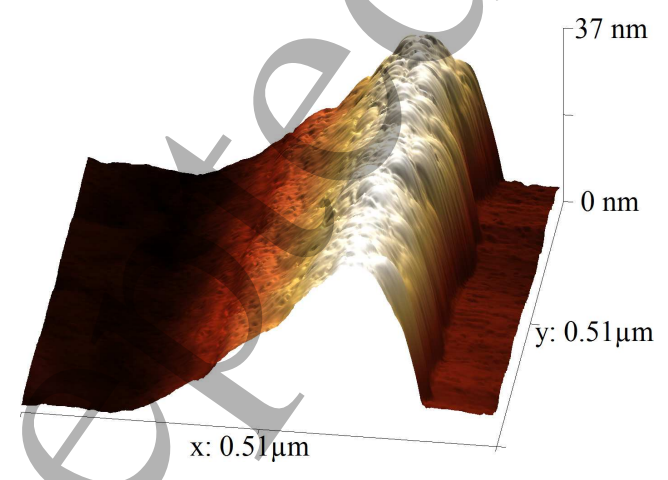

(a)

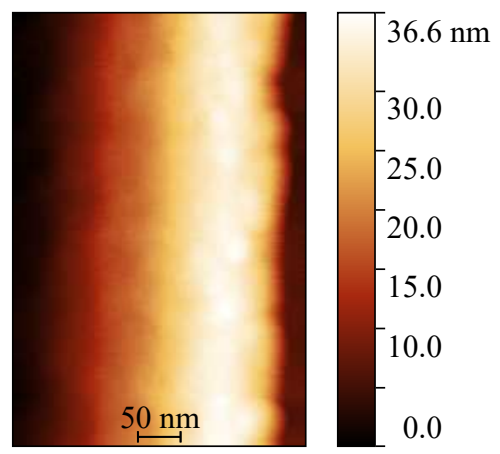

(b)

Figure 5. Atomic force microscopy image of a single $\mathrm{ZnO}$ nanowire top surface over a length of $500 \mathrm{~nm}$ : a) 3D plot of the nanowire shape, b) top surface $2 \mathrm{D}$ scan result 


\subsection{Transfer characteristic}

To investigate the ZnO NWFET operation performance, electrical characterisation was carried out using a semiconductor parameter analyser (Keysight Technologies B1500A) in the dark at room temperature. Drain current vs. gate source voltage $\left(I_{D} / V_{G S}\right)$ measurements were performed for NWFET arrays with 2, 4, 6, 10, 50 and 100 nanowires and varying channel lengths of $5 \mu \mathrm{m}, 15 \mu \mathrm{m}, 25 \mu \mathrm{m}, 35 \mu \mathrm{m}$, and $45 \mu \mathrm{m}$. As an example figure 6 shows the $I_{D} / V_{G S}$ characteristic for a NWFET with 2 and 100 nanowires at $V_{D S}=0.5 \mathrm{~V}$. While the $V_{t h}$ for a two nanowire transistor varies with the channel length, devices with 100 nanowires start to operate at a fixed gate voltage of 9 V. Figure 7 shows the $I_{D}$ vs. $V_{D}$ transistor output characteristics with gate sweeps from $5 \mathrm{~V}$ to 35 $\mathrm{V}$. Here a maximum output current of $33.4 \mu \mathrm{A}$ was measured.

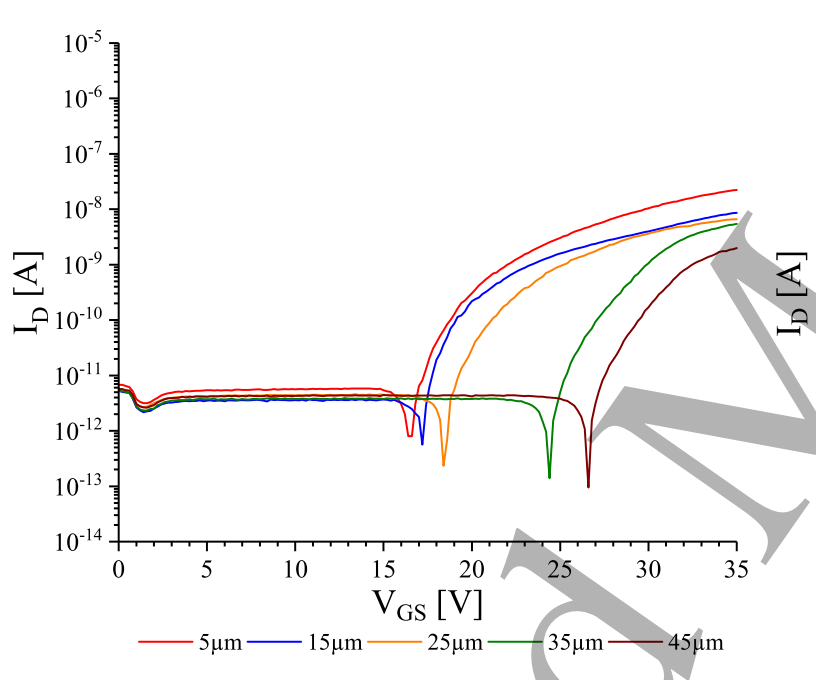

(a)

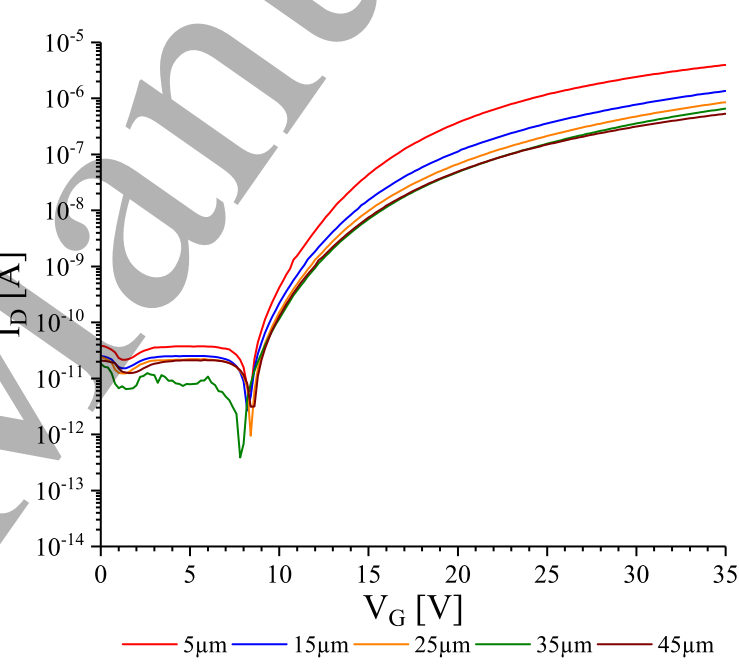

(b)

Figure 6. $I_{D}$ vs. $V_{G S}$ characteristic for passivated NWFETs with 2 (a) and 100 (b) nanowires and channel lengths between $5 \mu \mathrm{m}$ and $45 \mu \mathrm{m}$ at $V_{D S}=0.5 \mathrm{~V}$ 


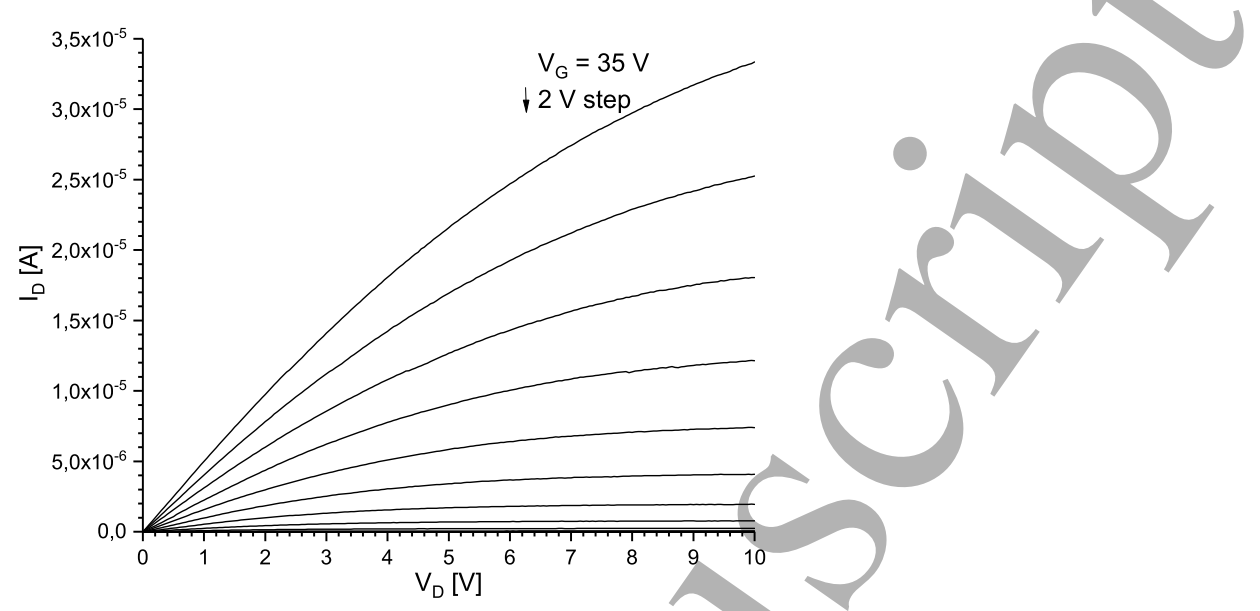

Figure 7. $I_{D}$ vs. $V_{D}$ output characteristics for gate sweeps from $5 \mathrm{~V}$ to $35 \mathrm{~V}$ with 2 V step size

Table 1 summarizes the measured $I_{D}$ drain current in the transistor saturation regime at a gate voltage of $35 \mathrm{~V}$ with applied drain voltage of $0.5 \mathrm{~V}$. It can be observed that the transistor output increases with the number of nanowires and decreases with longer channels. The lowest drain current of $2.0 \times 10^{-9} \mathrm{~A}$ was detected for a NWFET with two $45 \mu \mathrm{m}$ long nanowires and the maximum current of $4.0 x 10^{-6}$ was measured for a 100 nanowire FET with a channel length of $5 \mu \mathrm{m}$.

Table 1. drain current $I_{D}$ at $V_{G S}=35 \mathrm{~V}$ and $V_{D S}=0.5 \mathrm{~V}$ for NWFETs with 2 to 100 nanowires and channel lengths from $5 \mu \mathrm{m}$ to $45 \mu \mathrm{m}$

\begin{tabular}{crrrrr}
\hline number of nanowires & \multicolumn{5}{c}{$I_{D}[\mathrm{~A}]$ vs. channel length } \\
& $5 \mu \mathrm{m}$ & $15 \mu \mathrm{m}$ & $25 \mu \mathrm{m}$ & $35 \mu \mathrm{m}$ & $45 \mu \mathrm{m}$ \\
\hline 2 & $2.2 \times 10^{-8}$ & $8.6 \times 10^{-9}$ & $6.6 \times 10^{-9}$ & $5.5 \times 10^{-9}$ & $2.0 \times 10^{-9}$ \\
4 & $3.2 \times 10^{-8}$ & $3.1 \times 10^{-8}$ & $9.7 \times 10^{-9}$ & $6.6 \times 10^{-9}$ & $2.2 \times 10^{-9}$ \\
6 & $1.0 \times 10^{-7}$ & $4.3 \times 10^{-8}$ & $2.6 \times 10^{-8}$ & $1.9 \times 10^{-8}$ & $1.3 \times 10^{-8}$ \\
10 & $2.1 \times 10^{-7}$ & $1.2 \times 10^{-7}$ & $7.8 \times 10^{-8}$ & $5.4 \times 10^{-8}$ & $4.0 \times 10^{-8}$ \\
50 & $1.6 \times 10^{-6}$ & $5.4 \times 10^{-7}$ & $3.3 \times 10^{-7}$ & $2.9 \times 10^{-7}$ & $2.4 \times 10^{-7}$ \\
100 & $4.0 \times 10^{-6}$ & $1.4 \times 10^{-6}$ & $8.5 \times 10^{-7}$ & $6.6 \times 10^{-7}$ & $5.3 \times 10^{-7}$ \\
\hline
\end{tabular}

Table 2 compares the $I_{\text {on }} / I_{\text {off }}$ ratio vs. channel length by varying the number of nanowires. The highest value of $3.97 \times 10^{7}$ was found for a 100 channel $5 \mu \mathrm{m}$ long device, while the lowest $I_{o n} / I_{o f f}$ was observed for a two channel NWFET with a channel length of $45 \mu \mathrm{m}$. 
Table 2. $I_{o n} / I_{\text {off }}$ ratio for NWFETs with 2 to 100 nanowires and channel lengths from $5 \mu \mathrm{m}$ to $45 \mu \mathrm{m}$ at $V_{D S}=0.5 \mathrm{~V}$

\begin{tabular}{cccccc}
\hline number of nanowires & \multicolumn{5}{c}{$I_{\text {on }} / I_{\text {off }}$ vs. channel length } \\
& $5 \mu \mathrm{m}$ & $15 \mu \mathrm{m}$ & $25 \mu \mathrm{m}$ & $35 \mu \mathrm{m}$ & $45 \mu \mathrm{m}$ \\
\hline 2 & $2 x 10^{5}$ & $9 x 10^{4}$ & $7 x 10^{4}$ & $6 x 10^{4}$ & $2 x 10^{4}$ \\
4 & $3 x 10^{5}$ & $3 x 10^{5}$ & $1 x 10^{5}$ & $7 x 10^{4}$ & $2 x 10^{4}$ \\
6 & $1 x 10^{6}$ & $4 x 10^{5}$ & $3 x 10^{5}$ & $2 x 10^{5}$ & $1 x 10^{5}$ \\
10 & $2 x 10^{6}$ & $1 x 10^{6}$ & $8 x 10^{5}$ & $5 x 10^{5}$ & $4 x 10^{5}$ \\
50 & $2 x 10^{7}$ & $5 x 10^{6}$ & $3 x 10^{6}$ & $3 x 10^{6}$ & $2 x 10^{6}$ \\
100 & $4 x 10^{7}$ & $1 x 10^{7}$ & $9 x 10^{6}$ & $7 x 10^{6}$ & $5 x 10^{6}$ \\
\hline
\end{tabular}

\subsection{Transconductance and field effect mobility}

Figure 8 a) contrasts the transconductance $g_{m}$ of each device. The transconductance was extracted from the peak of the first derivative of the $I_{D} / V_{G S}$ curve at a $V_{D S}$ of $5 \mathrm{mV}$ to appreciate the carrier transport in the channel. Values range between $0.006 \mathrm{nS}(45 \mu \mathrm{m}$ and 2 nanowires) to $3.4 \mathrm{nS}$ (5 $\mu \mathrm{m}$ and 100 nanowires). These values are higher than top down fabricated NWFETs using the spacer technique [19], 21], but are still lower than single crystal ZnO NWFETs [14], [33]. All transistors demonstrate a dependency on

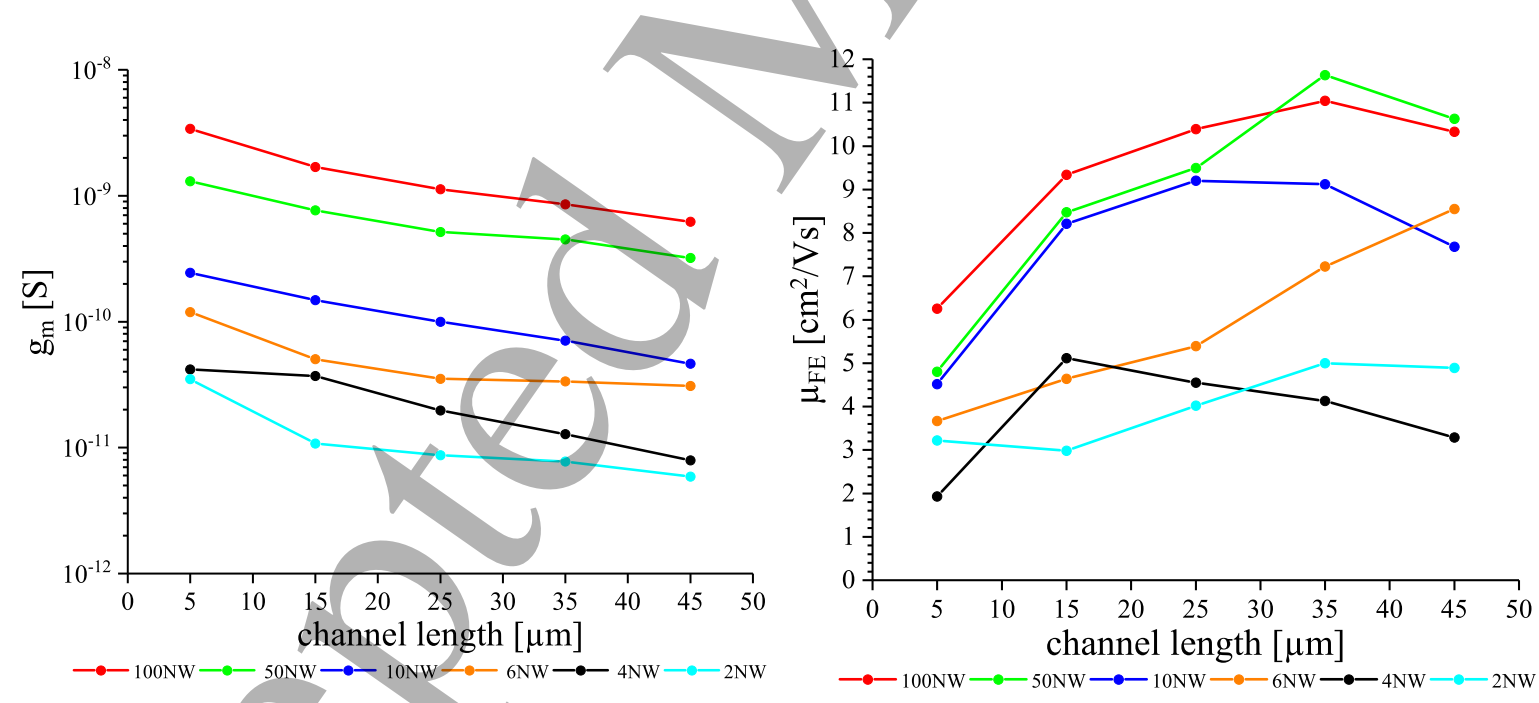

(a)

(b)

Figure 8. (a) Transconductance peak vs. channel length for NWFETs with 2 to 100 nanowires at $V_{D S}=5 \mathrm{mV}$; (b) Extracted field effect mobility vs. channel length for NWFETs with 2 to 100 nanowires at $V_{D S}=5 \mathrm{mV}$ (lines between data points are a guide for the eye)

the channel length, where the transconductance decreases with larger channel lengths. As the shape of the nanowires is rectangular and the back gate is planar, the field effect mobility $\mu_{F E}$ was extracted from the value of the transconductance peak using 
the standard MOSFET equation

$$
\mu_{F E}=\frac{C_{O x} V_{D S} w}{l g_{m} n_{N W}}
$$

where $C_{O x}$ refers to the back gate capacitance and was calculated from $C_{\mathrm{Ox}}=\varepsilon_{0} \varepsilon_{\mathrm{SiO}_{2}} / d$ (with oxide thickness $d$ ), $w$ is the nanowire width, $l$ is the channel length and $n_{N W}$ is the number of nanowires [34]. The graph in figure $8 \mathrm{~b}$ ) shows the correlation between field effect mobility, channel length and number of nanowires. The highest field effect mobility was $11.6 \mathrm{~cm}^{2} / \mathrm{Vs}$ for a $35 \mu \mathrm{m}$ long transistor with 50 nanowires, while the lowest value of $1.9 \mathrm{~cm}^{2} / \mathrm{Vs}$ was measured for a 4 nanowire transistor with a $5 \mu \mathrm{m}$ long channel.

\subsection{Threshold voltage and subthreshold slope}

The threshold voltage $V_{t h}$ of each NWFET was investigated using the SD method, published by Wong et. al. [35]. With this approach the second derivative of the $I_{D} / V_{G S}$ graph is calculated. The resulting maximum at a designated $V_{G S}$ can be used to estimate the $V_{t h}$ for nanowire channels of different length, as shown in figure $9 \mathrm{a}$ ). All the transistors show an enhancement mode operation. It can be observed that a
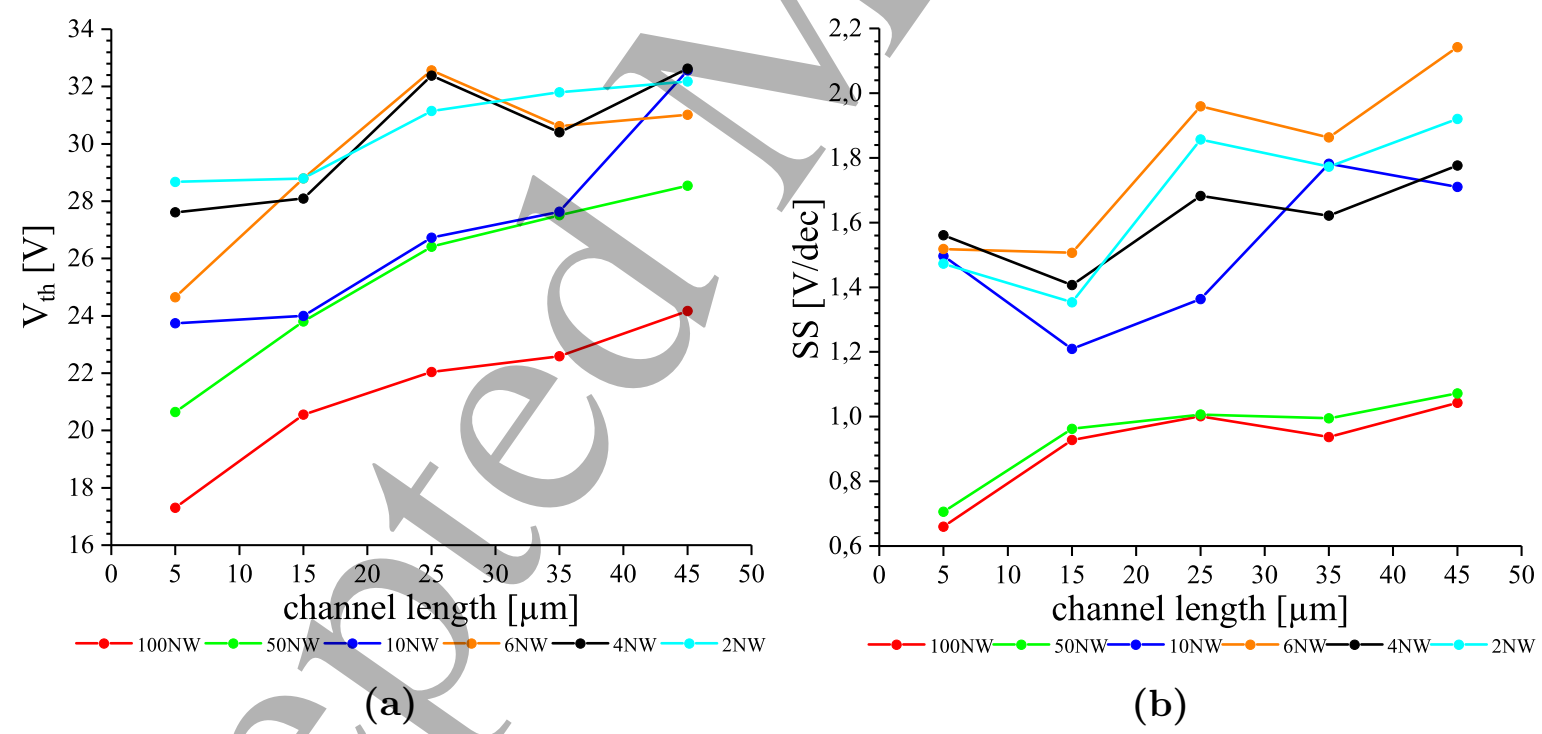

Figure 9. (a) Threshold voltage characteristic vs. channel length for NWFETs with 2 to 100 nanowires at $V_{D S}=0.5 \mathrm{~V}$; (b) Subthreshold slope characteristic between $I_{D}=10$ $\mathrm{pA}$ and $I_{D}=100 \mathrm{pA}$ vs. channel length for NWFETs with 2 to 100 nanowires at $V_{D S}$ $=0.5 \mathrm{~V}$ (lines between data points are a guide for the eye)

higher number of nanowires in the transistor leads to an average reduction of the $V_{t h}$ between 2 and 100 nanowires of $9.2 \mathrm{~V}$. Another impact can be found by varying the channel length. An average $V_{t h}$ decrease of $6.4 \mathrm{~V}$ for NWFETs with channel lengths between $5 \mu \mathrm{m}$ and $45 \mu \mathrm{m}$ was observed. Figure $9 \mathrm{~b})$ summarizes the results of the subthreshold slope measurement between the drain currents of $10 \mathrm{pA}$ and $100 \mathrm{pA}$ at $V_{D S}=0.5 \mathrm{~V}$. While transistors with 10 nanowires or less exhibit a subthreshold swing 
$S S$ of $1.2 \mathrm{~V} /$ dec to $2.2 \mathrm{~V} /$ dec, NWFETs with 50 and 100 nanowires show a significant reduction ranging from $1.07 \mathrm{~V} /$ dec to $0.66 \mathrm{~V} / \mathrm{dec}(5 \mu \mathrm{m}$ length and 100 nanowires)

\section{Discussion}

A new top-down fabrication method for ZnO NWFET devices was developed which eliminates key disadvantages of previous approaches. Compared to bottom-up methods this new technique can be used to fabricate reliable NWFET arrays with reproducible dimensions using standard UV lithography. For top-down processes this approach offers several advantages. With the spacer technique the nanowire size is determined by the trench dimensions. We adjusted the development time of the LOR3A photo resist to achieve a retrograde undercut. This method has been shown/successful in t-gate transistor fabrication [36], [37]. The fabrication flow developed in this study offers high reliability and reproducibility, by using only four low thermal budget processing tools (UV pattern tools, PEALD coater, ion beam etcher, metal evaporator). Process temperatures below $190{ }^{\circ} \mathrm{C}$ allow device fabrication on polymer substrates. PEALD exhibits excellent control of the deposition rate, which allows to change the nanowire height precisely. However, if the back gate dielectric is not planar, the nanowire channel will still experience a non-uniform field. Our bilayer resist method enables formation of planar nanowires on a dielectric material by removing the reversible photo resist template by lift off. From TEM and AFM inspection it can be seen that the nanowires exhibit a very smooth top surface. Any roughness results only from the ALD process. The retrograde resist profile protects the top surface of the nanowire from Ar ion bombardment during the anisotropic eteh.

All measured devices show a clear n-type enhancement transistor behaviour and indicate an improvement of electrical performance with increasing number of nanowires. The devices show clear scaling properties for the drain current in terms of the number of nanowires per device, as also observed by Regonda et al. [38]. NWFET biosensing applications will benefit from a better signal response due to steeper subthreshold slopes, higher mobilities and a better signal to noise ratio because of high drain currents and low off currents [39]. It can be also seen that the drain current follows an approximate scaling trend in terms of longer channel lengths. Here the back gating could change the effective length. The measurements showed NWFETs with small number of nanowires have higher threshold voltage $V_{t h}$, which line edge roughness can be the contributing (LER) effect. As reported by Hong et al. nanowire LER roughness has a significant effect on the electrical characteristics [40] and relies on the quality of the pattern transfer. Particle contamination during lithography can also lead to a significant increase of the LER. The impact of the electrical performance of a single irregularly shaped nanowire on the performance of a two-channel NWFET is much higher than that on a 100-channel transistor. This effect contributes to the increase of the $V_{t h}$ with a decreasing number of nanowires. A reduction of $V_{t h}$ with decreasing channel length can be attributed to short channel effects. Especially the drain induced barrier lowering was observed during 
$I_{D} / V_{G S}$ measurements (not shown) of one channel length with varying drain voltage, where the threshold voltage is reduced with higher values of $V_{D}$. The results in figure 8 b) show the field effect mobility values saturating as the channel length increases for different number of nanowires. This is also observed by Jo et. al., Luan et. al. and Sultan et. al. [41], [42], [43], where parasitic contact resistance, which we measured at $100 \mathrm{k} \Omega$ for the 100 nanowires transistor, at the source and drain region can affect the field effect mobility extraction. In addition, the large voltage drop over the parasitic contact resistance for the shorter channel devices would increase the electric field across the channel and electrons accumulation at the $\mathrm{ZnO}$ insulator surface, thus reducing the mobility through scattering effect [44]. The average the field effect mobility varies from $1.9 \mathrm{~cm}^{2} / \mathrm{Vs}$ to $11.6 \mathrm{~cm}^{2} / \mathrm{Vs}$, which correlates as well with the LER of nanowires, discussed above. Nanowires with lowest LER, will result in higher field effect mobilities due to less defects at the transistor channel. Therefore, these nanowires will dominate the transistors electrical characteristics. NWFETs with a high number of nanowires possess a high chance of exhibiting a high number well-defined channels.

The enhancement mode operation is assumed to correlate with grain boundary charges and trapped interface charges between the $\mathrm{ZnO}$ and the $\mathrm{SiO}_{2}$. Investigations on $\mathrm{ZnO}$ thin film structures have shown that double Schottky barriers form at every grain boundary and that deep acceptor traps affect the static and dynamic properties of the electron transport [45], [46]. Increasing the number of grain boundaries will reduce the field effect mobility of the transistor and influences the resistance within the nanowire channel [47], [48]. As a result the transistors operation regime will shift from a depletion mode to an enhancement mode [49]. A reduction of the grains inside of the $\mathrm{ZnO}$ crystal structure can be achieved by tuning the PEALD deposition process to temperatures of $100{ }^{\circ} \mathrm{C}$ [50]. To investigate whether the transistor can be shifted to a depletion mode, $I_{D}$ vs $V_{B G}$ measurements on a top gate biased 10 nanowire FET with a channel length of $15 \mu \mathrm{m}$ were carried out (figure $10 \mathrm{a}$ ). It can be seen that the transistors transfer curve can be shifted towards negative voltages. This is, because deep trap charges are pushed away by applying $V_{T G}$ on the transistor channel. Another source of trapped charges is attributed to deep level interfacial traps in the vicinity of the $\mathrm{ZnO} / \mathrm{SiO}_{2}$ interface [51], [52]. In this respect, $\mathrm{Al}_{2} \mathrm{O}_{3}$ is a promising alternative to $\mathrm{SiO}_{2}$, because of reduced dislocation, vacancy and interstitial defects and less deep trapped charge generation [53], [54]. For this reason another NWFET array with $100 \mathrm{~nm}$ wide nanowires was fabricated with a $30 \mathrm{~nm}$ thin $\mathrm{Al}_{2} \mathrm{O}_{3}$ back gate oxide layer instead of the $100 \mathrm{~nm} \mathrm{SiO}_{2}$ thin film. This thinner gate insulator also gives a higher dielectric constant. Figure $10 \mathrm{~b}$ ) shows the $I_{\mathcal{D}}$ vs $V_{G S}$ measurement at a $V_{D S}$ of $50 \mathrm{mV}$ where the $\mathrm{Al}_{2} \mathrm{O}_{3}$ back gate transistor switches on in the negative mode and operates in depletion mode. This experimental observation is indeed consistent with a reduction of interface charge injection. 


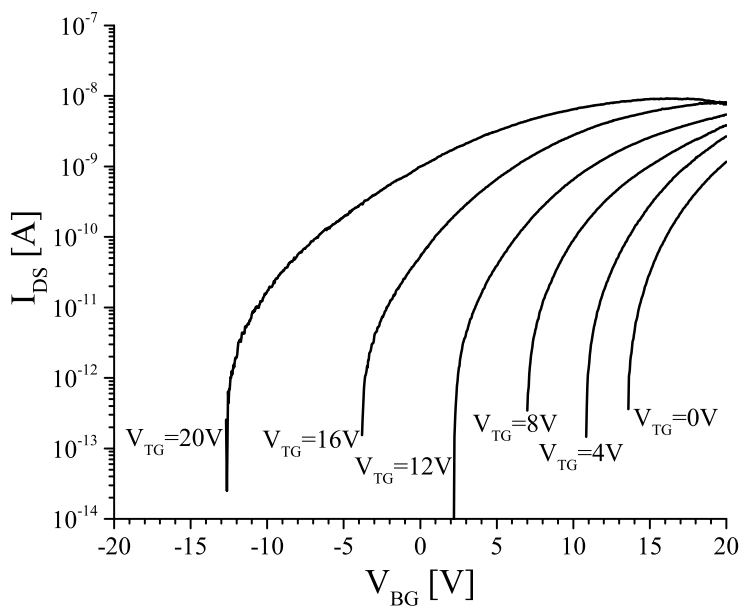

(a)

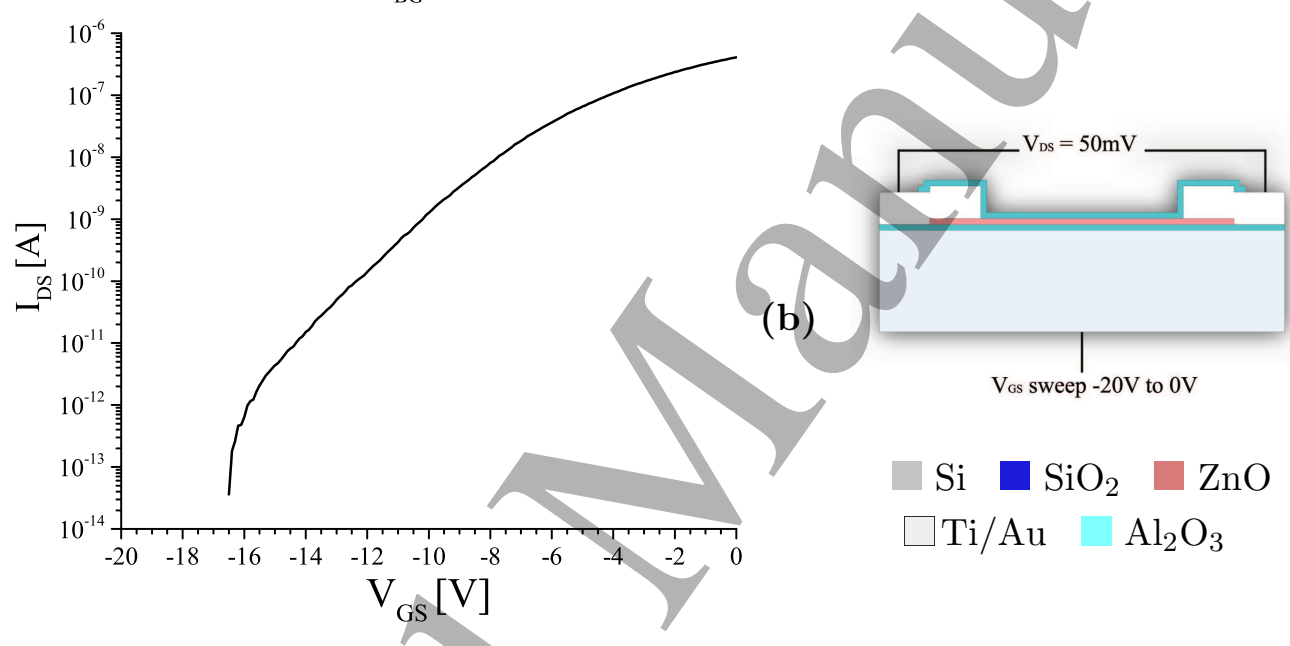

Figure 10. (a) $I_{D} / V_{B G}$ characteristic and measurement schematic for a 10 nanowire FET with $15 \mu \mathrm{m}$ channel length with a back gate sweep and static top gate voltages from $0 \mathrm{~V}$ to $20 \mathrm{~V}$ and a $V_{D S}=0.5 \mathrm{~V}$; (b) $I_{D} / V_{G S}$ characteristic and measurement schematic for a 100 nanowire FET with $15 \mu \mathrm{m}$ channel length with a $30 \mathrm{~nm}$ thick $\mathrm{Al}_{2} \mathrm{O}_{3}$ back gate at a $V_{D S}=50 \mathrm{mV}$

\section{Conclusion}

A scalable fabrication process for NWFET was developed which allows the formation of planar $\mathrm{ZnO}$ nanowire arrays on any type of gate dielectric layer using standard UV light lithography. Defining a wide range of NWFET configurations simultaneously enables rapid exploration of device performance parameters and identification of optimal parameters for specific applications, including biosensing. A retrograde bilayer photo resist pattern was investigated to reliably form nanowires scalable in number, length, width and height. The process benefits from low temperatures up to a maximum of $190{ }^{\circ} \mathrm{C}$, which allows fabrication of NWFET devices on any type of substrate, even polymer samples. SEM, TEM and AFM analysis show the reliable fabrication of the nanowire and a very smooth $\mathrm{ZnO}$ surface with a rms roughness of only $1.2 \mathrm{~nm}$, due to a very low impact of ion bombardment during IBE. Electrical measurements of the transistor arrays show a clear scalable regime, where an increase in the number of 
nanowires improves the electrical performance of the NWFET. Devices with the highest number of 100 nanowires per transistor show a field effect mobilities of $11.0 \mathrm{~cm}^{2} / \mathrm{Vs}$, a high $I_{o n} / I_{\text {off }}$ of $3.97 \times 10^{7}$ and a minimum subthreshold slopes of $0.66 \mathrm{~V} /$ dec. All NWFETs exhibit an enhancement mode behavior, which is assumed to correlate with grain boundary deep level trapped charges and $\mathrm{ZnO} / \mathrm{SiO}_{2}$ interface injection charges. Future work will include NWFET fabrication on polymer samples and investigations on their performance for biosensing applications.

\section{Acknowledgement}

M. E. would like to acknowledge the Norman Godinho PhD award from ECS. N.A.B. G. is grateful for her PhD support from the Malaysian Ministry of Education and Universiti Sains Malaysia. The authors would like to acknowledge the Southampton Nanofabrication Centre and Sustainable Electronics Technology Group for the fabrication and characterization support. 


\section{References}

[1] Pan H and Feng Y P 2008 ACS Nano 2 2410-2414

[2] Mu L, Chang Y, Sawtelle S D, Wipf M, Duan X and Reed M A 2015 IEEE Access 3 287-302 ISSN 2169-3536

[3] Lu J G, Chang P and Fan Z 2006 Materials Science and Engineering: R: Reports 52 49-91 ISSN 0927-796X

[4] Choi A, Kim K, Jung H I and Lee S Y 2010 Sensors and Actuators B: Chemical 148577 - 582 ISSN 0925-4005

[5] Liu X, Lin P, Yan X, Kang Z, Zhao Y, Lei Y, Li C, Du H and Zhang Y 2013 Sensors and Actuators B: Chemical $17622-27$ ISSN 0925-4005

[6] Niepelt R, Schröder U C, Sommerfeld J, Slowik I, Rudolph B, Möller R, Seise B, Csaki A, Fritzsche W and Ronning C 2011 Nanoscale Research Letters 6511 ISSD 1556-276X

[7] Jagadish C and Pearton S 2006 Zinc Oxide Bulk, Thin Films and Nanostructures. ((1)Australian National University: Elsevier Ltd) ISBN 9780080447223

[8] U O, Alivov Y I, Liu C, Teke A, Reshchikov M A, Doan S, Avrutin V, Cho S J and Morko H 2005 Journal of Applied Physics 98041301

[9] Hobbs R G, Petkov N and Holmes J D 2012 Chemistry of Materials 24 1975-1991

[10] Chang P C, Fan Z, Wang D, Tseng W Y, Chiou W A, Hong J and Lu J G 2004 Chemistry of Materials 16 5133-5137

[11] Huang H, Liang B, Liu Z, Wang X, Chen D and Shen G 2012 J. Mater. Chem. 22(27) 13428-13445

[12] Nasr B, Wang D, Kruk R, Rsner H, Hahn H and Dasgupta S 2013 Adv. Funct. Mater. 23 1750-1758 ISSN 1616-3028

[13] Kim H, Park J H, Suh M, Ahn J R and Ju S 2012 Applied Physics Letters 100063112

[14] Klblein D, Ryu H, Ante F, Fenk B, Hahn K, Kern K and Klauk H 2014 ACS Nano 8 6840-6848 pMID: 24940627

[15] He H, She J C, Huang Y F, Deng S Z and Xu N S 2012 Nanoscale 4(6) 2101-2108

[16] Cao T, Luo L, Huang Y, Ye B, She J, Deng S, Chen J and Xu N 2016 Scientific Reports 633983

[17] Tong H D, Chen S, van der Wiel W G, Carlen E T and van den Berg A 2009 Nano Letters 9 $1015-1022$

[18] Ra H W, Choi K S, Kim J H, Hahn Y B and Im Y H 2008 Small 4 1105-1109 ISSN 1613-6829

[19] Ditshego N, Sun K, Zeimpekis I, Ashburn P, de Planque M and Chong H 2015 Microelectronic Engineering 14591 - 95 ISSN 0167-9317

[20] Ditshego N M J, Ghazali N A B, Ebert M, Sun K, Zeimpekis I, Ashburn P, de Planque M R R and Chong H M H 2015 Zno nanowire-fet for charge-based sensing of protein biomolecules 2015 IEEE 15th International Conference on Nanotechnology (IEEE-NANO) pp 801-804

[21] Ghazali N, Ebert M, Ditshego N, de Planque M and Chong H 2016 Microelectronic Engineering 159121 - 126 ISSN 0167-9317 micro/Nano Devices and Systems 2015

[22] Jin S, Fischetti M V and wei Tang T 2007 Journal of Applied Physics 102083715

[23] Ra H W, Choi K S, Ok C W, Jo S Y, Bai K H and Im Y H 2008 Applied Physics Letters 93033112

[24] Widmann D W 1976 IEEE Journal of Solid-State Circuits 11 466-471 ISSN 0018-9200

[25] Tolstosheeva E, Barborini E, Meyer E M, Shafi M, Vinati S and Lang W 2014 Journal of Micromechanics and Microengineering 24015001

[26] Sun K, Zeimpekis I, Hu C, Ditshego N, Thomas O, de Planque M, Chong H, Morgan H and Ashburn P 2016 Microelectronic Engineering 15396 - 100 ISSN 0167-9317 micro- and Nanofabrication 2015

[27] Sultan S M, de Planque M R R, Ashburn P and Chong H M H 2017 Journal of Nanomaterials 20177

[28] Wilson T E, Korolev K A and Crow N A 2015 Journal of Micro/Nanolithography, MEMS, and MOEMS $1414-14-5$

[29] Beynet J, Wong P, Miller A, Locorotondo S, Vangoidsenhoven D, Yoon T H, Demand M, Park H S, 
Vandeweyer T, Sprey H, Yoo Y M and Maenhoudt M 2009 Low temperature plasma-enhanced ald enables cost-effective spacer defined double patterning (sddp) vol 7520 pp $7520-7520-7$

[30] Lee J M, Chang K M, Kim K K, Choi W K and Park S J 2001 Journal of The Electrochemical Society 148 G1-G3

[31] Pung S Y, Choy K L, Hou X and Shan C 2008 Nanotechnology 19435609

[32] C R P, G A C, B B O, E D A and A W C 2009 Chemical Vapor Deposition 15 15-20

[33] Cha S N, Jang J E, Choi Y, Amaratunga G A J, Ho G W, Welland M E, Hasko D G, Kang D J and Kim J M 2006 Applied Physics Letters 89263102

[34] Sze S and Ng K K 2006 Physics of Semiconductor Devices (John Wiley \& Sons, Inc.) ISBN 9780470068328

[35] Wong H S, White M H, Krutsick T J and Booth R V 1987 Solid-State Electronics 30953 - 968 ISSN 0038-1101

[36] Ocola L, Tennant D and Ye P 2003 Microelectronic Engineering 67-68 $104-108$ ISSN 0167-9317 proceedings of the 28th International Conference on Micro- and Nano-Engineering

[37] Hwu M J, Chiu H C, Yang S C and Chan Y J 2003 IEEE Electron Device Letters 24 381-383 ISSN 0741-3106

[38] Regonda S, Tian R, Gao J, Greene S, Ding J and Hu W 2013 Biosênsors and Bioelectronics 45 245 - 251 ISSN $0956-5663$

[39] Shen M Y, Li B R and Li Y K 2014 Biosensors and Bioelectronics 60101 - 111 ISSN 0956-5663

[40] Hong W K, Song S, Hwang D K, Kwon S S, Jo G, Park S J and Lee T 2008 Applied Surface Science 2547559 - 7564 ISSN 0169-4332

[41] Jo G, Maeng J, Kim T W, Hong W K, Jo M, Hwang H and Lee T 2007 Applied Physics Letters 90173106

[42] Luan S and Neudeck G W 1992 Journal of Applied Physics 72 766-772

[43] Sultan S M, Ditshego N J, Gunn R, Ashburn P and Chong H M 2014 Nanoscale Research Letters 9517 ISSN 1556-276X

[44] Huang Y, Duan X, Cui Y and Lieber C M 2002 Nano Letters 2 101-104

[45] Blatter G and Greuter F 1986 Phys. Rev. B 33(6) 3952-3966

[46] Bolognesi A, Berliocchi M, Manenti M, Carlo A D, Lugli P, Lmimouni K and Dufour C 2004 IEEE Transactions on Electron Devices 51 1997-2003 ISSN 0018-9383

[47] Hossain F M, Nishii J, Takagi S, Ohtomo A, Fukumura T, Fujioka H, Ohno H, Koinuma H and Kawasaki M 2003 Journal of Applied Physics 94 7768-7777

[48] Ohtomo A, Kimura H, Saito K, Makino T, Segawa Y, Koinuma H and Kawasaki M 2000 Journal of Crystal Growth 214-215 284 - 288 ISSN 0022-0248

[49] Bae H S and Im S 2004 Journal of Vacuum Science \& Technology B: Microelectronics and Nanometer Structures Processing, Measurement, and Phenomena 22 1191-1195

[50] jin Jin M, Jo J, Neupane G P, Kim J, An K S and Yoo J W 2013 AIP Advances 3102114

[51] Pierret R F, Gunshor R L and Cornell M E 1979 Journal of Applied Physics 50 8112-8124

[52] Lee K, Kim J H, Im S, Kim C S and Baik H K 2006 Applied Physics Letters 89133507

[53] Kim K K, Song J H, Jung,H J, Choi W K, Park S J and Song J H 2000 Journal of Applied Physics $873573-3575$

[54] Lee J B, Lee M H, Park C K and Park J S 2004 Thin Solid Films 447-448 296 - 301 ISSN 0040-6090 proceedings of the 30th International Conference on Metallurgical Coatings and Thin Films

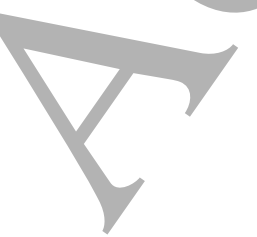

